\title{
SEX DIFFERENCES IN PRESENTATION, MANAGEMENT, AND PROGNOSIS OF PATIENTS WITH NON-SMALL CELL LUNG CARCINOMA
}

Marc de Perrot, MDa

Marc Licker, MD

Christine Bouchardy, $\mathrm{MD}^{\mathrm{c}}$

Massimo Usel, $\mathrm{BSc}^{\mathrm{C}}$

John Robert, MD

Anastase Spiliopoulos, $\mathrm{MD}^{\mathrm{a}}$
Objective and methods: To characterize gender differences in lung cancer, we conducted a retrospective analysis including all patients undergoing surgery for non-small cell lung carcinoma in a single institution over a 20-year period. Results: Compared with men $(n=839)$, women $(n=198)$ were more likely to be asymptomatic $(32 \%$ vs $20 \%, P=.006)$, nonsmokers $(27 \%$ vs $2 \%, P<.001)$, or light smokers $(31$ pack-years vs 52 pack-years; $P<.001)$. Squamous cell carcinoma predominated in men $(65 \%)$, and adenocarcinoma predominated in women (54\%). Preoperative bronchoscopy contributed more frequently to a histologic diagnosis in men (69\% vs $49 \%$ in women, $P<.001)$, and fewer pneumonectomies were performed in women $(22 \%$ vs $32 \%$ in men, $P=.01)$. After multivariate Cox regression analysis, women survived longer than men (hazard ratio, $0.72 ; 95 \%$ confidence interval, $0.56-0.92 ; P=.009$ ) independently of age, presence of symptoms, smoking habits, type of operation, histologic characteristics, and stage of disease. The protective effect linked to female sex was present in early-stage carcinoma (stage I and II) and absent in more advanced-stage carcinoma (stage III and IV). Conclusions: This study emphasizes strong sex differences in presentation, management, and prognosis of patients with non-small cell lung cancer. (J Thorac Cardiovasc Surg 2000;119:21-6)
A observed in North America and in most countries of northwestern Europe, lung cancer incidence has markedly changed in Switzerland over the past 2 decades. ${ }^{1,2}$ The incidence (standardized for age) for men increased until the $1980 \mathrm{~s}$ and then started to decline. In contrast, lung cancer incidence among Swiss women, which is much lower than that for men, started to increase later and is still on the rise.

Several authors have reported a more favorable prognosis of lung cancer in women than in men. ${ }^{3-6}$ In particular, we recently reported, from a population-based study performed in Geneva, that sex strongly influences the long-term survival expectancy independently of the effect of other widely known prognostic factors. ${ }^{7}$ However, this study, as well as others, was unable to

From the Thoracic Surgery Unit ${ }^{\mathrm{a}}$ and the Division of Anesthesiology, ${ }^{\mathrm{b}}$ University Hospital of Geneva, and the Geneva Cancer Registry, Geneva, Switzerland.

Received for publication April 28, 1999; revisions requested July 16, 1999; revisions received Oct 5, 1999; accepted for publication Oct 6, 1999.

Address for reprints: Anastase Spiliopoulos, MD, Thoracic Surgery Unit, Department of Surgery, University Hospital of Geneva, rue Micheli-du-Crest 24, 1211 Geneva 14, Switzerland.

Copyright $\odot 2000$ by Mosby, Inc.

$0022-5223 / 2000 \$ 12.00+0 \quad \mathbf{1 2 / 1 / 1 0 3 4 6 6}$ simultaneously take into account the contribution of specific clinical and therapeutic factors that could potentially explain longer survival among women. To better characterize sex differences, additional clinical and therapeutic information was collected retrospectively about patients undergoing surgery for non-small cell lung carcinoma (NSCLC) in our institution over a 20-year period.

\section{Patients and methods}

Between January 1, 1977, and December 31, 1996, 1046 patients underwent thoracotomy for NSCLC in the Thoracic Surgery Unit at the University Hospital of Geneva. According to the population-based cancer registry, this institution recruited more than $85 \%$ of all NSCLCs treated by operation in the canton of Geneva. Although no lung cancer-screening program was performed over the 20-year period in Geneva, chest radiography was usually performed for each new patient older than 50 years on admission to the hospital.

The charts of all patients were retrospectively reviewed, and data on patient age, preoperative symptoms, bronchoscopy findings, tobacco use in pack-years, type of surgical procedures, histologic type, stage of disease, adjuvant therapy, postoperative complications, and long-term outcome were retrieved. Nine patients (all men) were excluded because of incomplete documents. 
Table I. Sex differences in the type of signs and symptoms

\begin{tabular}{lccc}
\hline Symptoms & $\begin{array}{c}\text { Male subjects } \\
(n=839)\end{array}$ & $\begin{array}{c}\text { Female subjects } \\
(n=198)\end{array}$ & P value \\
\hline None & $153(20 \%)$ & $54(32 \%)$ & .006 \\
Cough & $84(11 \%)$ & $25(15 \%)$ & .3 \\
Hemoptysis & $242(32 \%)$ & $28(17 \%)$ & $<.001$ \\
Thoracic pain & $186(25 \%)$ & $28(17 \%)$ & .02 \\
Lung infection & $214(28 \%)$ & $32(19 \%)$ & .007 \\
Weight loss & $235(31 \%)$ & $39(23 \%)$ & .02 \\
Unknown & $84(10 \%)$ & $29(15 \%)$ & .08 \\
\hline
\end{tabular}

For patients resident in the canton, follow-up information was obtained from the Geneva Cancer Registry, as described previously. ${ }^{8}$ Briefly, in addition to passive follow-up (ie, routine examination of death certificates and of incidental findings in hospital records), active follow-up was carried out systematically by consulting the files of the Cantonal Population Office for all living patients at successive 5-year intervals after the incidence date. For the present study, the registry performed additional follow-up for patients operated on after January 1, 1993, to update the files up to January 1, 1998. For nonresident cases, follow-up information was obtained from hospital charts or phone calls to family physicians. Information on vital status was missing in 44 nonresident patients who were therefore excluded from survival analysis.

At initial presentation in the thoracic surgery unit, all patients were routinely and prospectively evaluated with a thorough medical history, physical examination, complete blood cell count, and blood chemistry and liver function tests. Chest radiography was systematically performed. In addition, computed tomographic (CT) scans of the chest and upper part of the abdomen were routinely performed since 1984. Bone scintigraphy and brain CT scan were obtained if indicated by clinical examination, abnormal laboratory values, or both. When enlarged mediastinal lymph nodes $(15 \mathrm{~mm}$ or more in the largest diameter) were detected on CT scanning, mediastinoscopy was included in the standard preoperative evaluation process. If mediastinal lymph nodes were found to be metastatic, patients were usually excluded from operations. The diagnosis of lung infection was made on the basis of the presence of fever, purulent sputum, and/or a new infiltrate on chest $\mathrm{x}$-ray film requiring antibiotic treatment. Ex-smokers were defined as patients who had stopped smoking before the diagnosis of lung carcinoma, regardless of the lapse of time since smoking arrest.

The type of resection was primarily dictated by the local extent of the tumor and secondarily by the cardiorespiratory function and general health status. All surgical procedures were performed either by staff surgeons or by senior residents under their direct supervision. With regard to pathologic staging of the tumor, patients underwent sampling of mediastinal lymph nodes before 1992 and systematic mediastinal dissection thereafter. Operative mortality included 30-day mortality rates, as well as any later deaths occurring during the initial hospital stay. Histologic typing was conducted according to the International Classification of Disease for Oncology. ${ }^{9}$ Tumor extent was determined postoperatively according to the revised pTNM classification. ${ }^{10}$

Patients with positive mediastinal lymph node involvement discovered postoperatively on histologic examination (pN2) usually underwent postoperative chemoradiotherapy. Radiotherapy was also given when the tumor cells infiltrated the resection margins. Since 1995, patients with N1 disease were included in an international randomized controlled trial to assess the effectiveness of postoperative chemotherapy (International Adjuvant Lung Cancer Trial). Induction therapy for N2 disease was initiated in 1997 and therefore was not applied to this patient series.

Characteristics of both sex groups were compared with the use of the $\chi^{2}$ or Student $t$ test where necessary. Survival was analyzed by the Kaplan-Meier method. Differences in survival were determined by using the log-rank test. Multivariate Cox regression analysis ${ }^{11}$ was used to test the independent effect of sex after accounting for age $(<60,60-69$, and $\geq 70$ years), preoperative symptoms (none, weight loss, and other symptoms), smoking habits $(0, \leq 40$, and $>40$ pack-years), type of surgical procedures (exploratory thoracotomy, pneumonectomy, and lesser resections), histology (squamous cell, adenocarcinoma, and other carcinomas), and stage of disease (I, II, III, and IV). By using the Cox model, we excluded 8 patients who died the day of surgery. To test whether sex differences differed according to a given tumor characteristic, we performed interaction tests ${ }^{12}$ by introducing, in the model interaction, terms involving sex and the characteristic of interest considering the same variables of adjustment.

\section{Results}

The group included 839 men and 198 women aged $61 \pm 9$ years (mean $\pm \mathrm{SD}$; range, 27 to 89 years) and 62 \pm 10 years (range, 34 to 82 years), respectively $(P=.8)$. The proportion of women was higher in the group of patients over 70 years ( $25 \%$ vs $19 \%$ in men, $P=.04$ ).

Modes of presentation differed significantly between the two sexes (Table I). Weight loss, hemoptysis, thoracic pain, and lung infection were observed more frequently in men. In contrast, the proportion of asymptomatic tumors discovered on routine chest $\mathrm{x}$-ray film was higher in women (32\% vs $20 \%$ in men, $P=.006$ ).

Data regarding smoking habits were available for $94 \%$ of patients. Most of the patients were current smokers or ex-smokers at the time of their presentation. However, the mean cigarette consumption was greater in men than in women $(52 \pm 25$ pack-years vs $31 \pm 27$ pack-years, respectively; $P<.001$ ), and women were much more likely to have a negative smoking history (27\% vs $2 \%$ in men, $P<.001$ ). This difference holds true in all types of NSCLC, although the proportion of 
Table II. Sex differences in histologic distribution and in mean survival time

\begin{tabular}{|c|c|c|c|c|c|c|}
\hline \multirow[b]{2}{*}{ Histology } & \multicolumn{3}{|c|}{ Histologic distribution } & \multicolumn{3}{|c|}{ Mean survival $(m o)^{*}$} \\
\hline & $\begin{array}{l}\text { Male subjects } \\
\quad(n=839)\end{array}$ & $\begin{array}{l}\text { Female subjects } \\
\quad(n=198)\end{array}$ & $\mathrm{P}$ value & $\begin{array}{c}\text { Male subjects } \\
\quad(n=804)\end{array}$ & $\begin{array}{l}\text { Female subjects } \\
\quad(n=189)\end{array}$ & $\mathrm{P}$ value \\
\hline All histologies & $839(100 \%)$ & $198(100 \%)$ & $<.001$ & 24 & 30 & .005 \\
\hline Squamous cell & $543(65 \%)$ & $62(31 \%)$ & $<.001$ & 25 & 24 & .7 \\
\hline Adenocarcinoma & $217(26 \%)$ & $106(54 \%)$ & $<.001$ & 22 & 32 & .01 \\
\hline Bronchoalveolar & $26(3 \%)$ & $18(9 \%)$ & $<.001$ & 32 & 50 & .3 \\
\hline Large cell & $38(4 \%)$ & $9(4 \%)$ & .9 & 12.5 & 13 & .7 \\
\hline Undifferentiated & $15(2 \%)$ & $3(2 \%)$ & .9 & 15 & 24 & .7 \\
\hline
\end{tabular}

"Forty-four patients lost to follow-up were excluded from survival analysis.

nonsmokers was lower in women with squamous cell carcinoma (16\%).

Men had the majority of squamous cell carcinomas (65\% vs $31 \%$ in women, $P<.0001$ ), whereas adenocarcinoma predominated in women $(54 \%$ vs $26 \%$ in men, $P<.0001$; Table II). The percentage of bronchoalveolar carcinoma was greater in women $(9 \%$ vs $3 \%$ in men, $P<.0001)$. Large cell and undifferentiated carcinomas were evenly distributed in the two sexes.

Bronchoscopy was performed in $90 \%$ of men and $80 \%$ of women, and its contribution to preoperative histologic diagnosis was higher in men than in women $(69 \%$ vs $49 \%, P<.001)$. In contrast, fine needle biopsy under fluoroscopy was performed more frequently in women $(17 \%$ vs $7 \%$ in men, $P<.001)$. Before surgery, the histologic diagnosis remained unknown in $26 \%$ of men and $43 \%$ of women $(P<.001)$.

Lung tumors were predominantly located in the upper lobes $(56 \%$ in both men and women, not significant). As shown in Table III, the proportion of pneumonectomy was greater in men (32\% vs $22 \%$ in women, $P=.01$ ), whereas more women underwent segmentectomy ( $11 \%$ vs $5 \%$ in men, $P=.007)$. With regard to tumor extension, a majority of patients had tumors of stage IA and IB (Table IV). A seemingly large proportion of patients underwent surgery for stage IIIB $(n=93)$ and IV $(n=37)$ disease. This finding is partly attributed to the new staging classification, which considers 2 separate lung nodules in the same lobe as T4 disease (stage IIIB) and 2 separate lung nodules in different lobes as M1 disease (stage IV).

No difference was observed in the distribution of adjuvant therapy between the two sex groups (25\% in men vs $23 \%$ in women, $P=.4$ ). In particular, 10 men and no women received adjuvant chemotherapy according to our protocol for N1 disease.

We observed a higher operative mortality rate in men compared with women (7\% vs 3\%, respectively) both after univariate analysis $(P=.07)$ and after additional
Table III. Sex differences in surgical procedures

\begin{tabular}{lccc}
\hline Surgery & $\begin{array}{c}\text { Male subjects } \\
(n=839)\end{array}$ & $\begin{array}{c}\text { Female subjects } \\
(n=198)\end{array}$ & P value \\
\hline All resections & $839(100 \%)$ & $198(100 \%)$ & .003 \\
Pneumonectomy & $265(32 \%)$ & $44(22 \%)$ & .01 \\
Bilobectomy & $51(6 \%)$ & $8(4 \%)$ & .3 \\
Lobectomy & $431(51 \%)$ & $110(55 \%)$ & .3 \\
Segmentectomy & $43(5 \%)$ & $21(11 \%)$ & .007 \\
Thoracotomy only & $49(6 \%)$ & $15(8 \%)$ & .5 \\
\hline
\end{tabular}

analyses accounting for the effects of age and type of surgery $(P=.06)$.

The mean follow-up was similar between men and women (48 and 44 months, respectively). In univariate analysis the overall mean survival time was greater in women than in men (30 months vs 24 months, respectively; $P=.005)$. This sex difference remained significant in the adenocarcinoma histologic type (Table II) and in the early tumoral stages (IA, IB, and IIB; Table IV). The difference was not statistically significant in stage IIA disease, most likely because of the small number of patients with T1 N1 disease $(n=44)$.

The effect of each factor on the instantaneous mortality rate estimated by multivariate analysis by using the Cox model analysis is reported in Table V. Tumor stage, presence of symptoms, smoking habits, and type of surgery were significantly linked to prognosis. Patients who lost weight carried a 1.87-fold increased risk of death (95\% confidence interval [CI], 1.46-2.40) compared with asymptomatic patients. Smokers had a significantly worse prognosis than nonsmokers (hazard ratio, 1.67; 95\% CI, 1.12-2.49). Although this smoking effect was present for all histologic types, we observed no significant differences between former and current smokers (hazard ratio, 0.89; 95\% CI, 0.62-1.29). Compared with pneumonectomy, lesser resections were associated with a trend toward a decreased risk of death (hazard ratio, 0.86; 95\% CI, 0.70-1.05), whereas 
Table IV. Sex differences in stage distribution and mean survival time

\begin{tabular}{|c|c|c|c|c|c|c|}
\hline \multirow[b]{2}{*}{ Stage } & \multicolumn{3}{|c|}{ Stage distribution } & \multicolumn{3}{|c|}{ Mean survival (mo) } \\
\hline & $\begin{array}{l}\text { Male subjects } \\
\quad(n=839)\end{array}$ & $\begin{array}{l}\text { Female subjects } \\
\quad(n=198)\end{array}$ & $\mathrm{P}$ value & $\begin{array}{l}\text { Male subjects } \\
\quad(n=804)\end{array}$ & $\begin{array}{l}\text { Female subjects } \\
\quad(n=189)\end{array}$ & $\mathrm{P}$ value \\
\hline IA & $166(20 \%)$ & $39(19 \%)$ & .9 & 91 & 117 & .04 \\
\hline IB & $231(28 \%)$ & $44(22 \%)$ & .2 & 40 & 68 & .02 \\
\hline IIA & $36(4 \%)$ & $8(4 \%)$ & .9 & 26 & 66 & .8 \\
\hline IIB & $169(20 \%)$ & $33(17 \%)$ & .3 & 16 & 43 & .01 \\
\hline IIIA & $132(16 \%)$ & $49(25 \%)$ & .004 & 14 & 15 & .7 \\
\hline IIIB & $79(9 \%)$ & $14(7 \%)$ & .4 & 8 & 5 & .8 \\
\hline IV & $26(3 \%)$ & $11(6 \%)$ & .1 & 9 & 10 & .9 \\
\hline
\end{tabular}

*Forty-four patients lost to follow-up were excluded from survival analysis.

Table V. Effect of prognostic factors on instantaneous mortality rate

\begin{tabular}{|c|c|c|c|c|}
\hline Variables & No. & Hazard ratio & $95 \% C I$ & $\mathrm{P}$ value \\
\hline \multicolumn{5}{|l|}{ Age (y) } \\
\hline$<60$ & 431 & 1 & Reference & \\
\hline $60-69$ & 373 & 1.2 & $1.02-1.41$ & .03 \\
\hline$\geq 70$ & 189 & 1.2 & $0.98-1.47$ & .08 \\
\hline \multicolumn{5}{|l|}{ After adjustment for age } \\
\hline \multicolumn{5}{|l|}{ Sex } \\
\hline Male & 804 & 1 & Reference & \\
\hline Female & 189 & 0.75 & $0.62-0.91$ & .004 \\
\hline \multicolumn{5}{|c|}{$\begin{array}{l}\text { After adjustment for age and } \\
\text { all other factors listed below }\end{array}$} \\
\hline \multicolumn{5}{|l|}{ Symptoms } \\
\hline None & 198 & 1 & Reference & \\
\hline Weight loss & 264 & 1.87 & $1.46-2.40$ & $<.001$ \\
\hline Other symptoms & 404 & 1.21 & $0.95-1.53$ & .1 \\
\hline \multicolumn{5}{|l|}{ Smoking habits } \\
\hline 0 pack-years & 62 & 1 & Reference & \\
\hline$<40$ pack-years & 378 & 1.82 & $1.22-2.72$ & .004 \\
\hline$>40$ pack-years & 494 & 1.48 & $0.99-2.21$ & .06 \\
\hline \multicolumn{5}{|l|}{ Type of surgery } \\
\hline Pneumonectomy & 293 & 1 & Reference & \\
\hline Lesser resections & 636 & 0.86 & $0.70-1.05$ & .1 \\
\hline Exploratory thoracotomy & 64 & 1.74 & $1.25-2.41$ & .001 \\
\hline \multicolumn{5}{|l|}{ Histology } \\
\hline Squamous cell & 577 & 1 & Reference & \\
\hline Adenocarcinoma & 310 & 1.19 & $0.97-1.45$ & .09 \\
\hline Other carcinomas & 106 & 1.35 & $1.02-1.77$ & .03 \\
\hline \multicolumn{5}{|l|}{ Stage } \\
\hline I & 458 & 1 & Reference & \\
\hline II & 225 & 1.82 & $1.45-2.28$ & $<.001$ \\
\hline III and IV & 310 & 3.06 & $2.45-3.82$ & $<.001$ \\
\hline \multicolumn{5}{|l|}{ Sex } \\
\hline Male & 805 & 1 & Reference & \\
\hline Female & 189 & 0.72 & $0.56-0.92$ & .009 \\
\hline $\begin{array}{l}\text { Combined effect of sex } \\
\text { and stage }\end{array}$ & & & & $.04^{*}$ \\
\hline Male and stage I, II & & 1 & Reference & \\
\hline Female and stage I, II & & 0.59 & $0.43-0.83$ & \\
\hline Male and stage III, IV & & 2.07 & $1.67-2.57$ & \\
\hline Female and stage III, IV & & 2.02 & $1.42-2.86$ & \\
\hline
\end{tabular}

Results are from a multivariate analysis with the Cox model. Patients lost to follow-up $(n=44)$ were excluded from analysis.

${ }^{*} \chi^{2}$ interaction test after adjustment for age, symptoms, smoking habits, type of surgery, histology, stage, and sex. 
exploratory surgery alone conferred a significant excess of risk (hazard ratio, 1.74; 95\% CI, 1.25-2.41), reflecting the absence of putative curative surgery.

Women were found to have a better prognosis than men independently of the effects of age, symptoms, smoking habits, type of surgery, histology, and stage of disease (hazard ratio, 0.72; 95\% CI, 0.56-0.92; Table V).

Significant interaction between sex and cancer stage on NSCLC prognosis was observed $(P=.04)$. The relative protection linked to female status was present in early-stage carcinoma (stage I and II; hazard ratio, 0.59; 95\% CI, 0.43-0.83), whereas it was absent (close to one) in more advanced stages (stage III and IV, Table $\mathrm{V})$. None of the other interactions, such as those between sex and histology (squamous cell, adenocarcinoma, and other carcinomas), sex and tobacco $(0, \leq 40$, and $>40$ pack-year), and sex and age $(<60,60-69$, and $\geq 70$ years) were statistically significant.

\section{Discussion}

In this retrospective study on more than 1000 patients undergoing lung resection for NSCLC, we observed strong differences between the sexes in tumor presentation, management, and prognosis.

Despite the large number of patients in the study, only $198(19 \%)$ were women, thus reflecting the male preponderance of lung carcinoma in Geneva. ${ }^{13}$ However, this represents one of the largest surgical series of women reported in the literature.

As we have previously reported during the 20-year interval of the study, improved perioperative care, as well as better staging modalities and refinements in both medical and radiation oncology, improved the 5year survival. ${ }^{14}$ Nonetheless, patients in either sex group were cared for equivalently, thus allowing valid intergroup comparisons.

In this series we observed striking differences in smoking habits between men and women. Whereas over $25 \%$ of women were nonsmokers, this rate remained at $2 \%$ in the male population. Furthermore, the mean cigarette consumption was significantly lower in smoking women than in men.

Such difference in smoking habits likely resulted in different clinical presentation, histology, and treatment. Squamous cell carcinoma was present in the majority of men in our series (65\%). Because these tumors are well known to predominate in heavy smokers and to develop from large and central bronchus, ${ }^{15,16}$ they are often difficult to detect by chest radiography at early stages because of the overlying hilar and mediastinal structures. Hence a large majority of the male subjects $(80 \%)$ demonstrated clinical signs, such as hemoptysis, lung infection, thoracic pain, or weight loss, by the time of surgery, and $32 \%$ of them underwent pneumonectomy.

In women, adenocarcinoma accounted for the majority of lung carcinoma (54\%). Because these tumors are usually located in the periphery of the lung, a greater proportion of women were asymptomatic (32\%). Pneumonectomy was less frequently performed and thus contributed to a lower operative mortality rate compared with that found in the male subjects. These data are consistent with those from the previous observations of Mitsudomi and colleagues ${ }^{17}$ in a group of Japanese patients undergoing surgery for NSCLC.

In addition to the widely known prognostic factors, such as stage and histologic characteristics, ${ }^{7}$ this study showed that sex, weight loss, and smoking habits also significantly influence the prognosis of NSCLC.

Better survival among women with lung carcinomas has already been demonstrated in a few previous studies, ${ }^{3-7}$ but the reason why such a sex difference exists remains obscure. Palomares and colleagues ${ }^{18}$ have reported that weight loss was a significant prognostic factor contributing to reduction of the long-term survival in men. Our study demonstrated that sex remained an independent prognostic factor, even after accounting for the different smoking distribution and weight loss pattern between men and women. The sex difference was also not explained by other differences in lung cancer presentation and management. In addition, we observed that the effect of sex was present only in early tumor stages.

These findings give further support to the hypothesis that the hormonal status may influence the prognosis of lung carcinoma. Indeed, the presence of estrogen receptors has been demonstrated on human lung cancer tissue, ${ }^{19-21}$ and these receptors, with their dependent intracellular processes, differed among the various types of lung carcinoma and stages of disease. ${ }^{22-24}$

Although the majority of women diagnosed with lung carcinoma are postmenopausal with low levels of circulating estrogens, reproductive hormones remain the most fertile area to explore. In our series there was no significant interaction between age and sex, and better prognosis remained present in women before and after the age of 50 years (data not shown).

Recently, the use of estrogen replacement therapy, as well as short menstrual cycles and late menopause, have been reported to increase the risk of lung adenocarcinoma in women. ${ }^{25,26}$ Further in vitro experiments have shown that 2-methoxyestradiol, which is an endogenous estrogen metabolite, suppressed tumor growth by inhibiting angiogenesis and inducing apop- 
tosis in human lung cancer cell lines. ${ }^{27,28}$ These initial results should strongly encourage additional studies on the interaction between sex and lung tumor characteristics to better clarify why and how sex could modify lung carcinogenesis.

We thank Dr L. Raymond for reviewing the manuscript.

\section{REFERENCES}

1. Coleman MP, Esteve J, Damiecki P, Arslan A, Renard H, editors. Trends in cancer incidence and mortality. IARC Scientific Publications, No. 121. Lyon: International Agency for Research on Cancer; 1993.

2. Janssen-Heijnen M. Trends in lung cancer incidence and survival: studies based on cancer registries. Netherlands: Venlo; 1998.

3. Paesmands M, Sculier JP, Libert P, et al. Prognostic factors for survival in advanced non-small cell lung cancer: univariate and multivariate analysis including recursive partioning and amalgamation algorithms in 1,052 patients. J Clin Oncol 1995;13:122130.

4. Ferguson MK, Skosey C, Hoffman PC, Golomb HM. Sex-associated differences in presentation and survival in patients with lung cancer. J Clin Oncol 1990;8:1402-7.

5. Ouellette D, Desbiens G, Emond C, Beauchamp G. Lung cancer in women compared with men: stage, treatment, and survival. Ann Thorac Surg 1998;66:1140-4.

6. Johnson BE, Steinberg SM, Phelps R, Veach SR, Ihde DC. Female patients with small cell lung cancer live longer than male patients. Am J Med 1988;85:194-6.

7. Bouchardy C, Fioretta G, de Perrot M, Spiliopoulos A, Obradovic M. Determinants of long-term survival after surgery for carcinoma of the lung. A population-based study. Cancer. In press.

8. Raymond L, Fischer B, Fioretta G, Bouchardy C. Migration bias in cancer survival rates. J Epidemiol Biostat 1996;1:167-73.

9. World Health Organization. International Classification of Diseases for Oncology, ICD-O. 1st ed. Geneva: World Health Organization; 1976.

10. Mountain CF. Revisions in the international system for staging lung cancer. Chest 1997;111:1710-7.

11. Cox DR. Regression models and life tables. J Roy Stat Soc B 1972;34:205-7.

12. Breslow NE, Day NE. Statistical methods in cancer research: the analysis of case-control studies. IARC Scientific Publications, Vol 1, No. 32. Lyon, France: International Agency for Research on Cancer; 1980.

13. Bouchardy C. Geneva, Switzerland. In: Parkin DM, Whelan SL,
Ferlay J, Raymond L, Young J, editors. Cancer incidence in five continents. Vol 7. IARC Scientific Publications, No. 143. Lyon: International Agency for Research on Cancer; 1997. p. 666-9.

14. de Perrot M, Licker M, Robert J, Spiliopoulos A. Time trend in the surgical management of patients with lung carcinoma. Eur J Cardiothorac Surg 1999;15:433-7.

15. Barbone F, Bovenzi M, Cavallieri F, Stanta G. Cigarette smoking and histologic type of lung cancer in men. Chest 1997;112:14749.

16. Bryd RB, Carr DT, Miller WE, et al. Radiographic abnormalities in carcinoma of the lung as related to histological cell type. Thorax 1969;24:573-5.

17. Mitsudomi T, Tateishi M, Oka T, Yano T, Ishida T, Sugimmachi K. Longer survival after resection of non-small cell lung cancer in Japanese women. Ann Thorac Surg 1989;48:639-42.

18. Palomares MR, Sayre JW, Shekar KC, Lillington LM, Chlebowski RT. Gender influence on weight-loss pattern and survival of nonsmall cell lung carcinoma patients. Cancer 1996;78: 2119-26.

19. Canver CC, Memoli VA, Vanderveer PL, Dingivan CA, Mentzer $\mathrm{RM}$ Jr. Sex hormone receptors in non-small cell lung cancer in human beings. J Thorac Cardiovasc Surg 1994;108:153-7.

20. Caltagirone S, Ranelletti FO, Rinelli A, et al. Interaction with type II estrogen binding sites and antiproliferative activity of tamoxifen and quercetin in human non-small-cell lung cancer. Am J Respir Cell Mol Biol 1997;17:51-9.

21. Cagle PT, Mody DR, Schwartz MR. Estrogen and progesterone receptors in bronchogenic carcinoma. Cancer Res 1990;50:6632-5.

22. Vargas SO, Leslie KO, Vacek PM, Socinski MA, Weaver DL. Estrogen-receptor-related protein p29 in primary nonsmall cell lung carcinoma: pathologic and prognostic correlations. Cancer 1998;82:1495-500.

23. Chaudhuri PK, Thomas PA, Walker MJ, Briele HA, Gupta TKD, Beattie CW. Steroid receptors in human lung cancer cytosols. Cancer Lett 1982;16:327-32.

24. Beattie CW, Hansen NW, Thomas PA. Steroid receptors in human lung cancer. Cancer Res 1985;45:4206-14.

25. Taioli E, Wynder E. Endocrine factors and adenocarcinoma of the lung in women. J Natl Cancer Inst 1994;86:869-70.

26. Gao YT, Blot WJ, Zheng W, et al. Lung cancer among Chinese women. Int J Cancer 1987;40:604-9.

27. Fotsis T, Zhang Y, Pepper MS, et al. The endogenous oestrogen metabolite 2-methoxyoestradiol inhibits angiogenesis and suppresses tumor growth. Nature 1994;368:237-9.

28. Mukhopadhyay T, Roth JA. Induction of apoptosis in human lung cancer cells after wild-type p53 activation by methoxyestradiol. Oncogene 1997;14:379-84. 